\title{
COMPETÊNCIA JUDICIAL INTERNACIONAL EM MATÉRIA DE CONTRATOS INDIVIDUAIS DE TRABALHO NA UNIÃO EUROPEIA: EUROPEIZAÇÃO DAS REGRAS DE CONFLITO NO REGULAMENTO BRUXELAS I REFORMULADO
}

Nicole Rinaldi de Barcellos ${ }^{1}$

Resumo: O objetivo do presente estudo é expor os fundamentos e a estrutura das regras de competência judicial internacional em matéria de contratos individuais de trabalho no âmbito do direito internacional privado da União Europeia, hoje previstas no Regulamento Bruxelas I Reformulado. A investigação divide-se em duas seções. A primeira versa sobre os fundamentos teóricos da europeização da competência internacional em contratos individuais de trabalho e a segunda versa sobre os aspectos normativos presentes no Regulamento Bruxelas I Reformulado sobre a matéria. O método de abordagem teórica é o dedutivo e o método de procedimento é a pesquisa bibliográfica e legislativa.

Palavras-chave: Europeização do direito internacional privado; Direito internacional privado do trabalho; Competência internacional; Contratos individuais de trabalho; União Europeia.

\section{INTERNATIONAL JURISDICTION OVER INDIVIDUAL CONTRACTS OF EMPLOYMENT IN THE EUROPEAN UNION: EUROPEANISATION OF CONFLICT OF LAW RULES IN THE BRUSSELS I REGULATION RECAST}

\begin{abstract}
The present study aims to discuss the fundamentals and the structure of the rules of international jurisdiction over individual contracts of employment in the framework of the private international law of the European Union, as determined by the Brussels I Recast Regulation. The research is divided into two sections. The first deals with the theoretical foundations of the Europeanisation of international competence in individual contracts of employment and the second concerns the normative aspects of the Brussels I Recast Regulation. The method of theoretical approach is the deductive and the procedure method is the bibliographical and legislative research.
\end{abstract}

Keywords: Europeanization of private international law; Private international labor law; International jurisdiction; Individual contracts of employment; European Union.

\footnotetext{
${ }^{1}$ Doutoranda e Mestre pelo Programa de Pós-Graduação em Direito da Universidade Federal do Rio Grande do Sul (PPGDir./UFRGS). Bolsista da Coordenação de Aperfeiçoamento de Pessoal de Nível Superior (CAPES). Endereço postal: Rua Casemiro de Abreu, 125/603, Porto Alegre - RS, Brasil, CEP 90.420-001. Endereço eletrônico: nicoledebarcellos@gmail.com.
} 


\section{INTRODUÇÃO}

O objetivo do presente estudo é expor o fundamento e a estrutura das regras de competência judicial internacional em matéria de contratos individuais de trabalho no âmbito do direito internacional privado da União Europeia, especialmente no que tange às regras de conflito de direito internacional privado do trabalho propostas no Regulamento Bruxelas I Reformulado. Pretende-se desvendar se as regras protetivas aos trabalhadores são coerentes com o sistema europeizado de competência.

Cuida-se de uma investigação acerca do fenômeno da europeização do direito internacional privado, por meio do qual a União Europeia passou a legislar em caráter supranacional sobre temas internacional privados com relevância ao bloco, como é o caso do direito internacional privado do trabalho em matéria de contratos individuais celebrados por trabalhadores (JAEGER JUNIOR, 2012; MOURA RAMOS, 2016). A pesquisa justifica-se pois o sistema europeizado de competência internacional mostra-se exemplar quanto à proteção dos vulneráveis, tornando-se relevante o estudo e a compreensão sobre o tema.

A pergunta de pesquisa a que se pretende responder com o presente estudo é: considerando-se os fundamentos da competência judicial internacional em matéria de contratos individuais de trabalho na União Europeia, as regras protetivas aos trabalhadores são coerentes com o sistema europeizado de competência? Para responder à pergunta, a investigação dividese em duas partes: a primeira versa sobre os fundamentos teóricos da europeização da competência internacional em contratos individuais de trabalho e a segunda sobre os aspectos normativos presentes no Regulamento Bruxelas I Reformulado sobre o tema.

O método de abordagem teórica é o dedutivo e o método de procedimento é a pesquisa bibliográfica e legislativa. Como marco teórico, adotam-se os autores Augusto Jaeger Junior e Dário Moura Vicente.

\section{FUNDAMENTOS TEÓRICOS DA EUROPEIZAÇÃO DA COMPETÊNCIA INTERNACIONAL EM CONTRATOS INDIVIDUAIS DE TRABALHO}

O direito internacional privado comporta temas como o conflito de leis e de jurisdições e a cooperação jurídica internacional. Em se tratando de conflito de jurisdições, para a definição da competência judicial internacional, encontra-se em discussão a definição do local onde a 
demanda será processada e julgada. Tais disputas também podem estar relacionadas ao direito internacional privado do trabalho, quando um trabalhador pretenda ajuizar uma demanda contra o seu empregador no caso de uma relação trabalhista plurilocalizada.

Segundo Dário Moura Vicente, o tema do conflito de jurisdições, ou da competência judicial internacional, volta-se tanto para o poder jurisdicional que pertence aos tribunais dos Estados para processar e julgar ações que tenham relação com duas ou mais ordens jurídicas, quanto para o poder reconhecido por determinada ordem jurídica aos tribunais de outro Estado para julgar ações que perante eles tenham corrido, como no reconhecimento de sentenças estrangeiras (2002a, p. 243).

Nesse sentido, a União Europeia ao longo de seu desenvolvimento, adquiriu competência para legislar sobre a matéria do direito internacional privado, tendo estabelecido instrumentos legislativos voltados à competência internacional. Desde o princípio, esses instrumentos contaram com uma proteção especial para os contratos individuais de trabalho.

A presente seção dedica-se ao estudo dos fundamentos teóricos da europeização do direito internacional privado, especialmente no tocante à competência internacional em matéria de contratos individuais de trabalho. No primeiro tópico é analisada a formação do sistema europeizado de competência internacional (ponto 1.1) e no segundo tópico é estudado o direito internacional privado do trabalho e as bases para a europeização da competência judicial internacional em matéria de contratos individuais de trabalho (ponto 1.2).

\section{FORMAÇÃO DO SISTEMA EUROPEIZADO DE COMPETÊNCIA INTERNACIONAL: DO CONVÊNIO DE BRUXELAS DE 1968 AO REgULAMENTO BRUXELAS I REFORMULADO DE 2012}

A União Europeia é um processo de integração regional supranacional ${ }^{2}$, com o objetivo de alcance da “pluralidade na diversidade”, formado hoje por 28 Estados-membros, que evoluiu gradativamente ao estabelecimento de um mercado interno no qual são garantidas as liberdades de circulação de bens, serviços, pessoas e capitais (MOLINA DEL POZO, 1997). Observa-se

\footnotetext{
${ }^{2}$ Joana Stelzer destaca que a supranacionalidade se volta à expressão de um mando superior aos Estados, resultante da transferência de soberania pelas unidades estatais, em benefício da comunitária, de forma a permitir a integração e a regulação de determinadas matérias que tenham importância para os objetivos integracionistas (STELZER, 2000, p. 67-68).
} 
que ao longo da evolução dos tratados na União Europeia houve uma gradativa transferência de competências dos Estados-membros ao órgão supranacional, sendo possível a criação de uma ordem comunitária (STELZER, 2000, p. 67-68) ${ }^{3}$.

A União Europeia passou então a legislar sobre temas relevantes ao processo de integração, como foi o caso da competência internacional, que se mostrou importante ao aprofundamento do processo integracionista, pois matéria relacionada à resolução de conflitos pluriconectados. Nesse sentido, Dário Moura Vicente destaca que a conciliação da desejada pluralidade na diversidade almejada pela integração Europeia somente pode ser alcançada por meio da adoção de medidas de uniformização das regras de conflito no âmbito do direito internacional privado (MOURA VICENTE, 2009, p. 179-220).

Segundo Augusto Jaeger Junior, o fenômeno da europeização do direito internacional privado consiste em um processo de gradativo abandono da utilização de legislações autônomas internas dos Estados-membros da União Europeia, valorizando-se a adoção de instrumentos de caráter supranacional que contêm regras de conflito (2012, p. 27). Tal situação pode ser observada na União Europeia em matéria de competência judicial internacional civil e comercial, que engloba os casos dos contratos individuais de trabalho, hoje prevista no Regulamento Bruxelas I Reformulado.

Destaca-se que a primeira matéria escolhida pelo legislador da União Europeia para regulamentação foi a competência internacional, junto ao reconhecimento e execução e decisões judiciais (MOURA RAMOS, 2016, p. 2-61). Esse interesse foi manifestado desde os primeiros anos de integração europeia, tendo em vista que o Tratado da Comunidade Econômica Europeia de 1957 já previa um compromisso aos Estados-membros de promoverem a efetivação das regras internacionais privadas, mas que tão somente dedicava-se à criação de instrumentos de caráter convencional e vinculados ao direito primário da União Europeia (BONOMI, 2009, p. 8), isto é, sujeitos à intergovernabilidade.

Com base nisso, foi instituído o Convênio de Bruxelas sobre a competência judicial e o reconhecimento e execução de decisões em matéria civil e comercial de 27 de setembro de 1968, ratificado pelos seis Estados-membros de então (Bélgica, Alemanha, França, Itália, Luxemburgo e Holanda), e posteriormente por todos os Estados que vieram a fazer parte da União Europeia (POCAR, 1978). O convênio estabeleceu regras sobre a competência

\footnotetext{
3 Segundo Marta Lucia Olivar Jimenez, essa ordem comunitária encontra-se caracterizada por três fatores fundamentais, a saber, a especificidade da nova ordem, a primazia em relação às ordens jurídicas internas e o efeito direto de diversas de suas disposições (OLIVAR JIMENEZ, 1997, p. 33-88).
} 
internacional em matérias civil e comercial, ainda que não contivesse, nesse momento, as previsões acerca dos contratos individuais de trabalho reunidas em um único título, mas ao longo de seu texto.

Com o Tratado de Maastricht, de 7 de fevereiro de 1992, previu-se uma competência específica da União Europeia para legislar sobre direito internacional privado, que permitiu que fossem adotadas medidas com a finalidade da melhoria da cooperação em matéria civil. No entanto, a possibilidade de estabelecimento de um direito internacional privado de fonte supranacional passou a ser prevista somente a partir do Tratado de Amsterdam, quando, segundo Augusto Jaeger Junior, passou-se a falar de um “direito internacional privado europeizado, de fonte supranacional, que tem a tendência de sobrepor-se aos sistemas jurídicos autônomos internos dos Estados-membros da União Europeia, e que poderia vir até mesmo a substitui-lo” (JAEGER JUNIOR, 2012, p. 67).

Isto porque com o Tratado de Amsterdam foi inserido o artigo 65 no antigo Tratado das Comunidades Europeias, que passou a servir de base legal à adoção de regulamentos e diretivas, pois esteve voltado à promoção da compatibilidade das normas aplicáveis nos Estadosmembros. Com ele, a legislação de direito internacional privado passou a se desenvolver. Segundo Andrea Bonomi, este foi o principal instrumento de impulsão à europeização do direito internacional privado, de forma a representar uma verdadeira revolução (2009, p. 8-9).

A reforma no tratado fundacional levou à instituição do Regulamento n. 44/2001 do Conselho, de 22 de dezembro de 2000, que foi o primeiro instrumento a unificar as regras de competência judicial em matéria civil e comercial, de origem supranacional, conhecido como Regulamento Bruxelas I. Na época, ele buscou a constituição de um espaço judiciário europeu (MOURA VICENTE, 2009, p. 299), estabelecendo regras para a competência internacional e para a circulação de decisões. Este regulamento foi posteriormente revogado, sendo substituído pelo Regulamento ${ }^{\circ} 1215$ de 12 de dezembro de 2012, ou Bruxelas I Reformulado.

Posteriormente, o Tratado de Lisboa de 2009 operou uma nova reforma nos tratados fundacionais, que levou ao estabelecimento das normas hoje em vigor. Nesse sentido, o atual artigo 81 do Tratado sobre o Funcionamento da União Europeia prevê uma competência para a uniformização das normas de direito internacional privado na União Europeia, com base na competência judiciária em matérias civis com incidência transfronteiriça. Com base neste 
artigo, estabeleceu-se o Regulamento n ${ }^{\circ} 1215$ de 12 de dezembro de 2012, aplicável a partir de 10 de dezembro de 2015, relativo à competência judiciária, ao reconhecimento e à execução de decisões em matéria civil e comercial, que revogou o Bruxelas $\mathrm{I}^{4}$ e é hoje o instrumento mais importante a regular o processo civil internacional na União Europeia. Ele é conhecido também como Bruxelas I Reformulado, e contém as regras de competência internacional em matéria de contratos individuais de trabalho, razão pela qual será explorado detalhadamente nos próximos tópicos do presente estudo.

Da menção aos instrumentos legislativos, destaca-se que o direito da União Europeia evoluiu gradativamente para a adoção de regras supranacionais em direito internacional privado, falando-se em um processo de europeização na matéria. Verifica-se uma estabilidade entre os instrumentos legislativos que se sucederam, podendo-se falar em uma organização sistemática da competência internacional em matérias civil e comercial. Hoje, importantes temas para o processo de integração, como é o caso da competência internacional, são previstos em um instrumento supranacional, na qual se inclui a matéria de contratos individuais de trabalho. Entendida a formação do sistema europeizado em matéria de competência internacional, passamos ao estudo de seus reflexos no direito internacional privado do trabalho, especialmente no tocante aos contratos individuais de trabalho, que são o objeto desse artigo.

\section{Direito INTERNACIONAL PRIVAdo do TRABALHO E AS BASES PARA A EUROPEIZAÇÃo dA COMPETÊNCIA JUDICIAL INTERNACIONAL EM MATÉRIA DE CONTRATOS INDIVIDUAIS DE TRABALHO}

A intensificação das relações privadas que tomam forma no plano internacional é profundamente influenciada pelo fenômeno da globalização econômica (FERNÁNDEZ ARROYO, 2011, p. 89-110), que deu origem a intensos fluxos transnacionais de bens e de pessoas (RAMOS, 2018, p. 23). Considerando em especial a seara trabalhista, a globalização econômica resultou em um aumento do intercâmbio de trabalhadores entre os países (CHAPARRO, 2003, p. 656), tendo em vista que são comuns a migração internacional dos trabalhadores, a internacionalização das atividades de empresas e a contratação de técnicos estrangeiros (MOURA RAMOS, 2002, p. 128-129).

\footnotetext{
${ }^{4}$ Ver: “Artigo 80. O presente regulamento revoga o Regulamento (CE) n. o 44/2001” (UNIÃO EUROPEIA, 2012).
} 
O direito, segundo Didier Opperti Badán, não pode permanecer à margem dessa etapa de evolução que envolve a comunidade internacional como um todo, pois o fenômeno pósmoderno da globalização demanda um exame próprio do direito, onde o tradicional esquema obediente às soberanias demonstra-se superado (2010, p. 36-37). Segundo o autor, reconhecese no direito internacional privado e em seus instrumentos um papel de ajuste de institutos jurídicos específicos, como é o caso da contratação internacional, que está estreitamente conectada ao mencionado fenômeno (OPPERTI BADÁN, 2010, p. 36-37).

Isto é, o direito internacional privado, como disciplina jurídica voltada à resolução de disputas privadas pluriconectadas, possui, em sua essência, uma função de gestão da diversidade das ordens jurídicas (RAMOS, 2018, p. 23-25) ${ }^{5}$. Ademais, o direito internacional privado é hoje um ramo jurídico que passa por uma renovação, à medida que em se constituindo um direito dos diferentes, dos estrangeiros e da localização das relações jurídicas privadas que atravessam as fronteiras, ele se volta à tutela dos mais fracos, com fins de proteção da pessoa humana (MARQUES; MIRAGEM, 2014, p. 97).

A adoção de uma nova compreensão e novas técnicas no direito internacional privado, segundo Nadia de Araújo, foi primordialmente influenciada pelas correntes migratórias de cunho econômico, observadas justo no caso da expansão do movimento dos trabalhadores (2018, p. 34). Isto significa dizer que as relações trabalhistas influenciaram profundamente a forma como o direito internacional privado é interpretado. Contemporaneamente, o direito internacional privado encontra-se vinculado à gramática dos direitos humanos (RAMOS, 2018, p. 61; JAYME, 2000).

Portanto, há uma ampla interconexão entre os ramos jurídicos do direito internacional privado e o direito do trabalho. Florisbal de Souza Del’Olmo e Augusto Jaeger Junior dispõem que diferentes vieses advém dessa ligação, de modo que o direito internacional privado do trabalho compõe-se do conjunto de regras de direito público interno que buscam solucionar os casos nos quais a lide trabalhista envolva mais de um ordenamento jurídico (2017, p. 308-309). Segundo os autores, a crescente participação de estrangeiros no mercado dos países,

\footnotetext{
${ }^{5}$ Segundo André de Carvalho Ramos, o Direito Internacional Privado é um conjunto de normas jurídicas nacionais e internacionais que tem a função e regular três grandes áreas, a saber, (i) a escolha de uma regra de regência sobre fatos transnacionais; (ii) a fixação de uma jurisdição para solucionar eventuais litígios sobre tais fatos; (iii) fórmulas de cooperação internacional entre Estados (2018, p. 25).
} 
possibilitada pela globalização, resulta em um considerável número de ações na justiça desses Estados.

Entretanto, Gilda Maciel Corrêa Meyer Russomano destaca que há uma especialidade dos conflitos de jurisdição e de leis envolvendo os trabalhadores, que se vincula ao fato de que as normas nacionais de direito do trabalho possuem papéis sociais diferentes, de modo que a aplicação das regras de conflitos demanda um cuidado voltado à proteção econômica do trabalhador (1964, p. 86). Segundo a autora, faz-se presente uma consciência jurídica de proteção dos trabalhadores como pessoas humanas, que sugere ao direito internacional privado soluções originais (1964, p. 80).

De acordo com Rui Manuel Moura Ramos, a constituição de espaços econômicos integrados contribui para o desenvolvimento de um direito internacional privado dos trabalhadores, tendo em vista que a aproximação de economias nacionais exige uma crescente mobilidade de participantes no processo produtivo, como é o caso dos trabalhadores e das empresas, que leva à regulamentação de aspectos relevantes na seara laboral (2002, p. 129). Segundo o autor, no âmbito da União Europeia, tal fato levou à expansão da competência supranacional em matéria de contratos individuais de trabalho.

Segundo Dário Moura Vicente, o deslocamento internacional de trabalhadores foi facilitado pelas liberdades de circulação de trabalhadores e de prestação de serviços consagradas pelo bloco, demandando uma europeização das regras internacional privadas (2002c, p. 86). Considerando essa delicada situação, a União Europeia previu regras especiais de competência internacional no Regulamento Bruxelas I Reformulado voltadas aos contratos individuais de trabalho, no âmbito das matérias civil e comercial. Esse regime especial encontra-se previsto no capítulo 2, seção 5, correspondente aos artigos 20 a 23 do Regulamento (UNIÃO EUROPEIA, 2012).

Peter Stone destaca que essas normas são inspiradas por uma preocupação em proteger a parte do contrato cuja expectativa é de que seja economicamente mais fraca e tenha menos experiência em questões jurídicas em relação à outra parte contratante (2011, p. 123). Nesse sentido, segundo Luís de Lima Pinheiro, a autonomização do regime especial voltado aos contratos individuais de trabalho é acompanhada de um reforço da proteção do trabalhador (LIMA PINHEIRO, 2012, p. 158).

De acordo com Augusto Jaeger Junior, a proteção dos trabalhadores foi fortalecida, pois se encontra em sintonia com as regras de proteção dos contratos de seguro e relativos aos 
consumidores (2012, p. 234), razão pela qual são previstas limitações à autonomia da vontade e regras de competência internacional protetivas. Portanto, o acervo normativo criado responde à preocupação de levar a justiça social ao seio das relações sociais, por meio da previsão de regras de competência internacional especiais aos contratos individuais trabalhistas (MOURA RAMOS, 2002, p. 130).

Estudada a relação entre o direito internacional privado do trabalho e a competência internacional especial aos contratos individuais do trabalho na União Europeia, passa-se à conclusão parcial. A europeização do direito internacional privado é hoje uma realidade, parte de um gradativo aprofundamento do processo de integração, e que foi influenciada pelos movimentos internacionais dos trabalhadores. Esse ramo jurídico foi influenciado também pelos direitos humanos, de modo que foram previstas regras de competência internacional especiais relativas aos contratos individuais de trabalho, voltadas à proteção dos trabalhadores. Nesse momento, passamos ao estudo da estrutura normativa presente no Regulamento Bruxelas I Reformulado.

\section{ESTRUTURA NORMATIVA DA COMPETÊNCIA JUDICIAL EUROPEIZADA EM MATÉRIA DE CONTRATOS INDIVIDUAIS DE TRABALHO}

Na lição de A. Ferrer Correia, um contato significativo de uma relação jurídica com determinado sistema jurídico é exigido para que sejam aplicadas as suas regras, também a competência internacional dos tribunais implica que a causa esteja ligada a um ordenamento determinado por uma conexão relevante (2017, p. 439-440). Segundo o autor, a competência internacional deve se justificar por um interesse considerável, tanto das partes, quanto da administração da justiça.

No caso dos contratos individuais de trabalho, a competência internacional encontra limitações quanto às possibilidades de ajuizamento da demanda e autonomia das partes, com fins de proteção da parte mais fraca, que é o trabalhador. A presente seção dedica-se à análise da estrutura normativa da competência judicial europeizada em matéria de contratos individuais de trabalho, voltando-se ao estudo dos âmbitos de aplicação do Regulamento Bruxelas I 
Reformulado (ponto 2.1) e à busca pela coerência na competência internacional europeizada em contratos individuais do trabalho (ponto 2.2).

\section{Âmbitos DE APLiCAÇão do REgulamento BRUXElas I REFORMUlado PARA A COMPETÊNCIA JUDICIAL INTERNACIONAL EM CONTRATOS INDIVIDUAIS DE TRABALHO}

Como já analisado neste estudo, o legislador da União Europeia optou pela reunião das regras especiais voltadas à competência internacional dos trabalhadores como forma de proteção dessa categoria jurídica, tendo em vista a crescente importância dos foros de proteção, que visam a restabelecer o equilíbrio de uma relação jurídica, através da tutela das partes vulneráveis (LOWENFELD, 1994, p. 77-78; FERNÁNDEZ ARROYO, 2006, p. 43). De acordo com Luís de Lima Pinheiro essa proteção é traduzida principalmente pela concessão à parte mais fraca de foros eletivos e a uma limitação aos pactos de jurisdição (2012, p. 136).

De plano, destaca-se que o conceito de contrato internacional de trabalho para os fins desse regulamento deve ser feita em consonância com o Regulamento Roma I. Segundo Luís de Lima Pinheiro ele volta-se para o caráter subordinado da atividade, que exclui as prestações de serviços realizadas através de qualquer atividade independente (2012, p. 136) ${ }^{6}$.

Os âmbitos de aplicação do Regulamento Bruxelas I Reformulado consistem nas hipóteses de utilização do direito da União Europeia no que tange às regras de conflitos de jurisdição. O presente estudo filia-se à classificação adotada por Augusto Jaeger Junior (2012, p. 213-220), que os divide em âmbitos material, temporal, pessoal e espacial.

O âmbito de aplicação material geral cinge-se aos temas civis e comerciais, aplicandose o Regulamento, especificamente a este estudo, aos contratos individuais de trabalho. Como delimitação negativa, são excluídas matérias fiscais, aduaneiras ou administrativas, a responsabilidade do Estado, e outras matérias especiais, como estado e capacidade jurídica das pessoas singulares, regimes de bens do casamento ou de parcerias, obrigações de alimentos decorrentes de uma relação familiar, parentesco, casamento ou afinidade. O âmbito de aplicação temporal delimita-se aos procedimentos instaurados após a sua entrada em vigor, em 10 de janeiro de 2015. Considerando-se que ele foi promulgado em substituição ao Regulamento

\footnotetext{
${ }^{6} \mathrm{Na}$ teoria, Amílcar de Castro define o contrato individual de trabalho como sinalagmático e de extrema importância social, no qual o empregado decide trabalhar para o empregador sob a direção deste, mediante remuneração em dinheiro (1965, p. 182).
} 
44/2001 (Regulamento Bruxelas I), este continua aplicável aos procedimentos anteriormente instaurados.

No que tange ao âmbito de aplicação espacial, o regulamento encontra-se válido em todos os 28 Estados-membros da União Europeia. Quanto ao âmbito de aplicação pessoal, destaca-se que o regulamento determina os órgãos jurisdicionais dos vários Estados-Membros que são competentes para decidir sobre um litígio em matéria civil e comercial quando existe um elemento internacional, desde que a entidade patronal ou a sua filial tenham domicílio na União Europeia.

Com isso, passa-se à análise das regras de competência da União Europeia propriamente ditas, que são de caráter bilateral, de forma a distribuírem a competência entre os Estadosmembros da União Europeia (JAEGER JUNIOR, 2012). Com fins de comparação, destaca-se que a regra geral de competência na União Europeia é o domicílio ou a residência habitual do demandado, conforme previsão do artigo $4^{\circ}$ (UNIÃO EUROPEIA, 2012). Essa escolha do legislador ocorre por razões pragmáticas, pois o foro do domicílio habitual do demandado representa o centro da vida, no local onde o interessado fixou voluntariamente o seu centro de interesses em caráter estável (CARRASCOSA GONZÁLES, 2015, p. 18), como um critério objetivo (LAGARDE, 1986, p. 138-142).

No que tange aos contratos individuais de trabalho, quatro são os artigos que regulamentam a competência internacional, a saber, os artigos 20 a 23, integrantes da seção 5 do capítulo 1 do Regulamento Bruxelas I Reformulado.

Considera-se aplicável o Regulamento Bruxelas I Reformulado e competente o tribunal de determinado Estado-membro da União Europeia, observadas as regras de distribuição da competência, quando a entidade patronal tiver domicílio em algum dos Estados-membros. No entanto, segundo o artigo 20, quando a entidade patronal não tiver domicílio em qualquer dos Estados-membros, considera-se competente o domicílio da filial, agência ou outro estabelecimento em um Estado-Membro, quanto aos litígios resultantes do funcionamento dessa filial, agência ou estabelecimento.

De acordo com o artigo 21, um trabalhador pode demandar a entidade patronal que tenha domicílio em um Estado-membro, e com a qual tenha celebrado um contrato individual de trabalho, (i) nos tribunais em que tiver domicílio e (ii) no tribunal de outro Estado-membro, 
quando este for o lugar onde ou a partir do qual o trabalhador efetua habitualmente o seu trabalho, ou no tribunal do lugar onde efetuou mais recentemente o seu trabalho, ou se o trabalhador não efetua ou não efetuava habitualmente o seu trabalho num único país, onde se situa ou se situava o estabelecimento que contratou o trabalhador.

Portanto, a competência internacional em matéria de contratos individuais de trabalho vincula-se especialmente ao local onde o trabalhador efetua habitualmente ou ao seu domicílio. Assim, no sistema do Regulamento, os tribunais dos locais nos quais o trabalhador foi temporariamente destacado não possuem competência para julgar o caso decorrente desse contrato, (MOURA VICENTE, 2002b, p. 313), salvo se este local coincidir com o domicílio do trabalhador ou da entidade patronal.

Além disso, segundo Luís de Lima Pinheiro, justifica-se a competência do tribunal onde se situa o último local no qual o trabalho foi efetuado, em vista de que o litígio frequentemente surge após a finalização do contrato individual de trabalho (2012, p. 159) Quanto ao lugar onde o trabalhador efetua habitualmente o seu trabalho, quando o contrato for efetuado em vários estados contratantes, de acordo com o estabelecido no caso Rutten pelo Tribunal das Comunidades Europeias de então, é o local no qual o trabalhador fixou o centro efetivo das suas atividades profissionais (TRIBUNAL DE JUSTIÇA DAS COMUNIDADES EUROPEIAS, 1997).

De acordo com o artigo 22 do Regulamento, a entidade patronal fica restrita ao domicílio do trabalhador quando intencionar ajuizar qualquer ação relativa ao contrato individual de trabalho deste. Entretanto, tal disposição não prejudica o direito da entidade patronal de formular um pedido reconvencional no tribunal em que tiver sido intentada a ação principal. Segundo Rui Manuel Moura Ramos, há uma valorização na facilitação do acesso à jurisdição por parte do contraente mais fraco, que é o trabalhador, ao mesmo tempo em que resta restringida a via do contraente mais forte, justamente obrigando ao ajuizamento da demanda no foro mais próximo ao vulnerável (2002, p. 157-162).

Por fim, quanto aos acordos de escolha de foro, o artigo 23 do Regulamento dispõe que as partes somente podem derrogar ao disposto na seção relativa aos contratos individuais de trabalho quando os acordos forem posteriores ao surgimento do litígio ou permitam ao trabalhador recorrer a tribunais que não sejam os indicados na mencionada seção. De acordo com Rui Manuel Moura Ramos os pactos atributivos de competência são verificados em casos restritivos e de eficácia limitada, com fins de evitar a desigualdade de posição dos contraentes, 
com fins de evitar que a parte mais forte escolha um tribunal desfavorável a sua contraparte, e consequentemente frustre os objetivos da proteção (2002, p. 157-162).

No presente tópico foram analisados os âmbitos de aplicação do Regulamento Bruxelas I Reformulado, especialmente no que tange aos contratos individuais de trabalho, demonstrando-se que em sede de conflito de jurisdições, o legislador da União Europeia dedicou-se à proteção dos trabalhadores. Tal fato foi constatado pela análise dos artigos 20 a 23 do referido instrumento legislativo. Com isso, passa-se ao estudo da coerência entre as regras protetivas aos trabalhadores e o sistema europeizado de competência, no que tange à estabilidade, à supranacionalidade e à proteção da parte mais fraca.

\section{Pela CoERÊNCIA NA COMPETÊNCIA INTERNACIONAL EUROPEIZADA EM CONTRATOS} INDIVIDUAIS DO TRABALHO: ESTABILIDADE, SUPRANACIONALIDADE E PROTEÇÃO DA PARTE MAIS FRACA

Augusto Jaeger Junior destaca que o direito da União Europeia tem servido à europeização do direito internacional privado a partir da utilização de regulamentos (2016, p. 138), que servem como um instrumento de alcance da uniformidade no sistema, tendo em vista que destinados à uniformização jurídica no âmbito do bloco. Os regulamentos são fontes de direito derivado e de alcance geral, diretamente aplicáveis aos Estados-membros e obrigatórios (MOLINA DEL POZO, 1997, p. 464).

A União Europeia adquiriu, em seus tratados fundacionais, competência para legislar sobre o direito internacional privado por meio de regulamentos, mesmo que tenha sido resguardada a competência dos Estados-membros na matéria. Entretanto, mesmo que permaneçam os sistemas nacionais de competência, estes são aplicáveis somente de forma subsidiária, o instrumento supranacional falhou em regular a questão, nos termos do disposto por Alfonso Luis Calvo Caravaca e Javier Carrascosa Gonzáles (2005, p. 519). Isto é, as regras supranacionais de competência judicial são utilizadas pelos Estados-membros da União Europeia também em litígios com conexão internacional ainda que em relação a países terceiros (JAEGER JUNIOR, 2012, p. 206). 
Por outro lado, a União Europeia é a única competente para celebrar acordos internacionais quando tal celebração esteja prevista num ato legislativo da União e seja necessária para lhe dar a possibilidade de exercer a sua competência interna. Com isso, demonstra-se que a União Europeia possui os meios de promover a coerência no sistema de competência internacional em geral e em relação ao regime especial aos trabalhadores, pois detém a competência para legislar supranacionalmente e para celebrar acordos sobre competência judicial civil e comercial, que incluem os contratos individuais de trabalho.

Veja-se que o processo de integração no âmbito da União Europeia pressupõe uma constante comunicação entre os ordenamentos jurídicos nacionais e a ordem supranacional, segundo Véra Maria Jacob de Fradera, de tal modo que as suas relações se revistam de um necessário caráter dialético, aproximando-se umas das outras para formarem um conjunto coerente de normas (2010, p. 154). Isto porque, de acordo com Fausto de Quadros, o primeiro e mais relevante princípio da União Europeia é o princípio da integração, segundo o qual prevalece uma visão comunitária, de um poder integrado, com o objetivo de criação de interesses comuns entre a ordem supranacional e os Estados-membros (2002, p. 299).

Outro fator relevante é que o Tribunal de Justiça da União Europeia tem competência para uniformizar a interpretação das regras de competência internacional em matéria de contratos individuais de trabalho, por meio do reenvio prejudicial. Veja-se que esse sistema não é novo, à medida que o Convênio de Bruxelas de 1969 contava com um instrumento semelhante, sendo possível a produção de uma coerência interpretativa desde o princípio da legislação europeizada (STONE, 2011, p. 5; JAEGER JUNIOR, 2016, p. 142).

Segundo Dário Moura Vicente, hoje é possível falar em um Direito Processual Civil Europeu, que tem como objeto os processos que tenham conexão com mais de uma ordem jurídica nacional, formado pelos instrumentos legislativos próprios da União Europeia e pelas convenções internacionais celebradas pelos seus Estados-membros e a Associação Europeia de Comércio Livre (EFTA), sobre a matéria (2002b, p. 291-324).

O legislador da União Europeia, nesse sentido, dispôs no considerando 4 do Regulamento Bruxelas I Reformulado que as disparidades das regras nacionais em matéria de competência judiciária dificultam o bom funcionamento do mercado interno, mostrando indispensáveis disposições destinadas a unificar as regras de conflito de jurisdição em matéria civil e comercial (UNIÃO EUROPEIA, 2012). Quanto aos regimes protetivos, no considerando 14, o legislador destaca que a fim de assegurar de trabalhadores, salvaguardar a competência 


\section{COMPETÊNCIA JUDICIAL INTERNACIONAL EM MATÉRIA DE CONTRATOS INDIVIDUAIS DE TRABALHO NA UNIÃO EUROPEIA: EUROPEIZAÇÃO DAS REGRAS DE CONFLITO NO REGULAMENTO BRUXELAS I REFORMULADO}

dos tribunais dos Estados-Membros em situações em relação às quais têm competência exclusiva e respeitar a autonomia das partes, algumas normas de competência constantes do presente regulamento aplicam-se independentemente do domicílio do requerido (UNIÃO EUROPEIA, 2012), ainda que seja possível a adoção do domicílio pelo trabalhador.

Com isso, destaca-se que há uma linha condutora na regulamentação da competência internacional na União Europeia como um todo, tendo em vista que ela adota como fundamentos a proteção das pessoas domiciliadas nos Estados-membros, o princípio da proximidade, a proteção da parte mais fraca na relação jurídica e a autonomia da vontade (MOURA VICENTE, 2002b, p. 304). Segundo Augusto Jaeger Junior, há uma sintonia entre os casos dos contratos de consumo, de seguro e de trabalho, levando a um fortalecimento das regras protetivas à medida que partes de um todo (2012, p. 234).

De acordo com Claudia Lima Marques e Bruno Miragem a tendência mundial é a da proteção dos vulneráveis no direito internacional privado, que hoje é influenciado pelos direitos fundamentais, como é o caso do trabalhador (2014, p. 102), e isso pode ser observado no direito internacional privado da União Europeia. Portanto, verifica-se uma irradiação dos direitos humanos em tópicos tradicionais do direito internacional privado, como lei aplicável e jurisdição, renovando-se o discurso dos conteúdos e de conceitos (OPPERTI BADÁN, 2013, p. 72), que promovem uma coerência no sistema, como linhas mestras.

Por fim, destaca-se que há uma estabilidade nas regras europeizadas de direito internacional privado voltadas ao contrato individual de trabalho, tendo em vista que a na União Europeia desde o Convênio de Bruxelas de 1968 até do Regulamento Bruxelas I Reformulado de 2012 previu regras próprias aos trabalhadores, ainda que nem sempre em um título próprio. Os 60 anos do sistema de Bruxelas para a competência em matérias civil e comercial com regras estáveis levam à conclusão de que existe uma aceitação por parte dos Estados-membros desse regime, sendo possível verificar uma coerência do sistema como um todo.

O doutrinador Jürgen Basedow destaca que a coerência no direito internacional privado da União Europeia, deve ter um papel não só na política legislativa, mas também na aplicação da lei, como um desígnio relacionado à sistemática jurídica, de forma a representar uma característica do sistema jurídico (2016, p. 56-77). Portanto, a coerência deve ser parte do aquis communautaire, promovendo-se uma harmonia no que tange ao estabelecimento e à aplicação 
das regras de competência judiciária civil e comercial e das regras protetivas, como é o caso dos trabalhadores.

Como conclusão parcial desta parte do estudo, destaca-se que a União Europeia se destacou em uma proteção europeizada no que tange aos contratos individuais de trabalho, voltada à escolha do tribunal do Estado-membro que seja mais benéfico ao trabalhador. Essas normas são coerentes com as regras gerais presentes no Regulamento Bruxelas I Reformulado, tendo em vista uma linha das mestras que o conduz é a proteção das partes mais fracas, observando-se a influência dos direitos humanos.

\section{CONSIDERAÇÕES FINAIS}

O presente estudo dedicou-se à análise dos fundamentos e da estrutura normativa da competência judicial internacional em matéria de contratos individuais de trabalho no âmbito do direito internacional privado da União Europeia. Foi possível verificar que a europeização do direito internacional privado faz parte do processo integracionista e hoje possui como fio condutor a proteção dos direitos humanos.

É nesse cenário que são estabelecidas as regras especiais de competência internacional, como aquelas voltadas à proteção dos trabalhadores, tendo em vista que estes são as partes mais fracas de uma contratação internacional. Nesse sentido é que foram previstas as normas de competência internacional especiais aos contratos individuais de trabalho nos artigos 20 a 23 do Regulamento Bruxelas I Reformulado.

Com isso, retoma-se a pergunta de pesquisa proposta no princípio deste estudo: considerando-se os fundamentos da competência judicial internacional em matéria de contratos individuais de trabalho na União Europeia, as regras protetivas aos trabalhadores são coerentes com o sistema europeizado de competência?

A resposta é sim. Com o presente estudo foi possível verificar uma coerência sistemática no que tange às regras de competência especiais dos trabalhadores e as regras gerais, tendo em vista que o sistema é voltado para a proteção dos direitos humanos, possuindo uma uniformização supranacional, uma interpretação unificada pelo Tribunal e uma coordenação entre as regras existentes no âmbito do Regulamento.

\section{REFERÊNCIAS}


ARAUJO, Nadia de. Direito Internacional Privado: Teoria e Prática Brasileira. 7 ed. rev. atual. ampl. São Paulo: Revista dos Tribunais, 2018. 478 p.

BASEDOW, Jürgen. Coerência do direito internacional privado da União Europeia. In: JAEGER JUNIOR, Augusto (Org.). Europeização da parte geral do direito internacional privado: estudos sobre uma codificação do direito internacional privado na União Europeia através de um Regulamento Roma Zero. Porto Alegre: Editora RJR, 2016. p. 51-77.

BONOMI, Andrea. Il diritto Internazionale privato dell'Unione Europea: considerazioni generali. In: BONOMI, Andrea (Ed.). Diritto Internazionale privato e cooperazione giudiziaria in materia civile. Torino: G. Giappichelli Editore, 2009. p. 1-54

CALVO CARAVACA, Alfonso Luis; CARRASCOSA GONZÁLES, Javier. Competencia judicial internacional: régimen de producción interna en derecho internacional privado español. In: DREYZIN DE KLOR, Adriana; FERNÁNDEZ ARROYO, Diego; PIMENTEL, Luiz Otávio. Litígio judicial internacional. Florianópolis: Fundação Boiteux, 2005. p. 519-542.

CARRASCOSA GONZÁLES, Javier. El concepto de residência habitual del causante em el reglamento sucesorio europeo. Revista Castellano-Manchega de Ciencias Sociales, n. 19. Azuqueca de Henares: Asociación Castellano-Manchega de Sociología, 2015. p. 15-35.

CASTRO, Amílcar de. Do trabalho em direito internacional privado. Revista da Faculdade de Direito da Universidade Federal de Minas Gerais, n. 5. Belo Horizonte: Faculdade de Direito da UFMG, 1965. p. 180-195.

CHAPARRO, Verônica Zárate. O estrangeiro à luz do direito internacional e do direito brasileiro: breves considerações. In: DEL’OLMO, Florisbal de Souza. Curso de direito internacional contemporâneo: estudos em homenagem ao Prof. Dr. Luis Ivani de Amorim Araújo pelo seu 80 aniversário. Rio de Janeiro: Forense, 2003. p. 655-683.

DEL'OLMO, Florisbal de Souza; JAEGER JUNIOR, Augusto. Curso de Direito Internacional Privado. $12^{\mathrm{a}}$ ed. Rio de Janeiro: Forense, 2017.

FERNÁNDEZ ARROYO, Diego P. Compétence exclusive et compétence exorbitante dans les relations privées internationales. Recueil de Cours, v. 323. La Haye: Académie de Droit International de La Haye, 2006. 259 p.

El Derecho Internacional Privado en el Inicio del Siglo XXI. In: ARAUJO, Nadia de; MARQUES, Claudia Lima (Org.). O novo direito internacional: estudos em 
homenagem a Erik Jayme. Rio de Janeiro: Renovar, 2005, p. 03-20; ARAUJO, Nadia de. Direito Internacional Privado: Teoria e Prática Brasileira. 5. ed. rev. e atual. Rio de Janeiro: Renovar, 2011. 89-109 p.

FERRER CORREIA, A. Lições de Direito Internacional Privado I. Coimbra: Almedina, 2017. $546 \mathrm{p}$.

FRADERA, Vera Maria Jacob de. Reflexões sobre a contribuição do direito comparado para a elaboração do direito comunitário. Belo Horizonte: Del Rey, 2010. 423 p.

JAEGER JUNIOR, Augusto. Europeização do direito internacional privado: caráter universal da lei aplicável e outros contrastes com o ordenamento jurídico brasileiro. Curitiba: Juruá Editora, 2012. 672 p.

. Europeização do direito internacional privado: recentes intercorrências no caminho de um Regulamento Roma Zero. In: JAEGER JUNIOR, Augusto (Org.). Europeização da parte geral do direito internacional privado: estudos sobre uma codificação do direito internacional privado na União Europeia através de um Regulamento Roma Zero. Porto Alegre: Editora RJR, 2016. p. 133-174.

JAYME, Erik. Le droit international privé du noveau millenaire: la protection de la personne humaine face à la globalisation. Conférence. Recueil des Cours, v. 282. La Haye: Académie de Droit International de La Haye, 2000. 40 p.

LAGARDE, Paul. Le principe de proximité dans le droit international privé contemporain. Recueil de Cours, v. 196. La Haye: Académie de Droit International de La Haye, 1986. 319 p.

LIMA PINHEIRO, Luís de. Direito internacional privado: competência internacional e reconhecimento de decisões estrangeiras. v. 3. Coimbra: Almedina, 2002. 617 p.

LOWENFELD, Andreas F. International litigation and the quest for reasonabless. Collected Courses, v. 196. The Hague: Hague Academy of International Law, 1994. 320 p.

MARQUES, Claudia Lima; MIRAGEM, Bruno. O novo direito privado e a proteção dos vulneráveis. 2. ed. rev. atual. ampl. São Paulo: Revista dos Tribunais, 2014. 256 p.

MOLINA DEL POZO, Carlos Francisco. Manual de derecho de la Comunidad Europea. 3. ed. Madrid: Editora Trivium, 1997. 953 p.

MOURA RAMOS, Rui Manuel. Introdução ao direito internacional privado da União Europeia: da interacção originária do direito internacional privado e do direito comunitário à criação de um direito internacional privado da União Europeia. In: MOURA RAMOS, Rui Manuel; MONACO, Gustavo Ferraz de Campos (Coords). Aspectos da Unificação Europeia do Direito Internacional Privado. São Paulo: Intelecto, 2016. p. 3-61. 
O contrato individual de trabalho no direito internacional privado. In: MOURA RAMOS, Rui Manuel. Estudos de direito internacional privado e de direito processual civil internacional. Coimbra: Coimbra Editora, 2002. p. 128-166.

MOURA VICENTE, Dário. A competência internacional no Código de Processo Civil Revisto: Aspectos Gerais. In: MOURA VICENTE, Dário. Direito Internacional Privado: Ensaios. v. 1. Coimbra: Almedina, 2002a. p. 243-266.

. Competência judiciária e reconhecimento de decisões estrangeiras no Regulamento (CE) no 44/2001. In: MOURA VICENTE, Dário. Direito Internacional Privado: Ensaios. v. 1. Coimbra: Almedina, 2002b. p. 291-324.

. Deslocamento internacional de trabalhadores. In: MOURA VICENTE, Dário. Direito Internacional Privado: Ensaios. v. 1. Coimbra: Almedina, 2002c. p. 85-106.

. Liberdades comunitárias e direito internacional privado. Cuadernos de derecho transnacional, v. 1, n. 2. Madrid: Carlos III, 2009. p. 179-220.

OLIVAR JIMENEZ, Martha Lucía. La compreensión de la noción de derecho comunitario para una verdadera integración en el Cono Sur. In: BASSO, Maristela (Org.). Mercosul: seus efeitos jurídicos, econômicos e poíticos nos estados-membros. Porto Alegre: Livraria do Advogado, 1997. p. 33-88.

OPPERTI-BADÁN, Didier. Reflexiones sobre las relaciones entre globalización y el derecho internacional privado. p. 31-53. In: MORENO RODRÍGUEZ, José A. Derecho internacional privado - derecho de la libertad y respeto mutuo: ensayos a la memoria de Tatiana $\mathrm{B}$. de Maekelt. Assunção: Centro de Estudios de Derecho, Economía y Política (CEDEP), 2010, p. 31-53.

. Reflexiones sobre un tema esencial: Derecho Internacional Privado e Derechos Humanos. In: Derecho internacional privado y derecho de la integración: Libro homenaje a Roberto Ruiz Díaz Labrano. Assunção: Centro de Estudios de Derecho, Economía y Política (CEDEP), 2013. p. 63-86. 
POCAR, Fausto. Jurisdiction and the enforcement of judgements under the EC convention of 1968: a review of court decisions. Rabels Zeitschrift für ausländisches und internationales Privatrecht/ The Rabel Journal of Comparative and International Private Law, Jahrg. 42, H. 3. Tübingen: Mohr Siebeck GmbH \& Co. KG, 1978. p. 405-430.

QUADROS, Fausto de. Direito da União Europeia: Direito Constitucional e Administrativo da União Europeia. 3. reimp. Coimbra: Almedina, 2009. 606 p.

RAMOS, André de Carvalho. Curso de Direito Internacional Privado. São Paulo: Saraiva Educação, 2018. 551 p.

RUSSOMANO, Gilda Macial Corrêa Meyer. Os conflitos espaciais de leis no plano das relações trabalhistas. Rio de Janeiro: José Konfino Editor, 1964. 2018 p.

STELZER, Joana. União Europeia e supranacionalidade: desafio ou realidade? Curitiba: Juruá, 2000. 198 p.

STONE, Peter. EU Private International Law. 2. ed. Cheltenham, UK; Northampton, USA: Edward Elgar, 2011. 562 p.

TRIBUNAL DE JUSTIÇA DAS COMUNIDADES EUROPEIAS. Caso 9/1/1997. Disponível em:

http://curia.europa.eu/juris/showPdf.jsf;jsessionid=9ea7d2dc30d631ca40bb01a344cab78483a 8069564bd.e34KaxiLc3qMb40Rch0SaxyLb3f0?text=\&docid=100700\&pageIndex=0\&doclag =PT\&mode=lst\&dir=\&occ=first\&part=1\&cid=611962 >. Acesso em: 23 mar. 2018.

UNIÃO EUROPEIA. Convenção de Bruxelas de 1968 relativa à Competência Jurisdicional e à Execução de Decisões em matéria civil e comercial. Disponível em: < https://eurlex.europa.eu/legal-content/PT/TXT/PDF/?uri=CELEX:41968A0927(01)\&from=PT $>$. Acesso em: 23 mar. 2018.

Regulamento (CE) $n^{\circ}$ 44/2001, do Conselho de 22 de Dezembro de 2000, relativo à competência judiciária, ao reconhecimento e à execução de decisões em matéria civil e comercial. Disponível em: $\quad<\quad \underline{\text { https://eur-lex.europa.eu/legal- }}$ content/PT/TXT/PDF/?uri=CELEX:32001R0044\&from=PT >. Acesso em: 23 mar. 2018. 
Regulamento (UE) no 1215/2012, do Parlamento Europeu e do Conselho, de 12 de dezembro de 2012, relativo à competência judiciária, ao reconhecimento e à execução de decisões em matéria civil e comercial. Disponível em: < https://eur-lex.europa.eu/legalcontent/PT/TXT/PDF/?uri=CELEX:32012R1215\&from=PT >. Acesso em: Acesso em: 23 mar. 2018.

Tratado da Comunidade Econômica Europeia. Disponível em: < https://eurlex.europa.eu/legal-content/PT/TXT/HTML/?uri=LEGISSUM:xy0023\&from=PT >. Acesso em: 23 mar. 2018.

Tratado sobre o Funcionamento da União Europeia. Disponível em: < $\underline{\text { https://eur- }}$ lex.europa.eu/resource.html?uri=cellar:9e8d52e1-2c70-11e6-b497-

01aa75ed71a1.0019.01/DOC_3\&format=PDF >. Acesso em: 23 mar. 2018. 